\section{Perceptions of racism in healthcare among patients with systemic lupus erythematosus: a cross-sectional study}

\author{
Ernest R Vina, ${ }^{1}$ Leslie R M Hausmann, ${ }^{2,3}$ Tammy O Utset, ${ }^{4}$ Christopher M Masi, ${ }^{4,5}$ \\ Kimberly P Liang, ${ }^{3} \mathrm{C}$ Kent Kwoh ${ }^{1}$
}

To cite: Vina ER,

Hausmann LRM, Utset TO, et al. Perceptions of racism in healthcare among patients with systemic lupus erythematosus: a crosssectional study. Lupus Science \& Medicine 2015;2: e000110. doi:10.1136/lupus2015-000110

- Additional material is available. To view please visit the journal (http://dx.doi.org/ 10.1136/lupus-2015000110).

Received 18 June 2015 Revised 28 July 2015 Accepted 30 July 2015

CrossMark

${ }^{1}$ University of Arizona School of Medicine and University of Arizona Arthritis Center, Tucson, Arizona, USA ${ }^{2}$ VA Pittsburgh Healthcare System, Pittsburgh, Pennsylvania, USA ${ }^{3}$ University of Pittsburgh School of Medicine, Pittsburgh, Pennsylvania, USA

${ }^{4}$ University of Chicago Pritzker School of Medicine, Chicago, Illinois, USA ${ }^{5}$ NorthShore University Health System, Evanston, Illinois, USA

Correspondence to Dr Ernest R Vina; evina@email.arizona.edu

\section{ABSTRACT}

Background: Racial disparities in the clinical outcomes of systemic lupus erythematosus (SLE) exist. Perceived racial discrimination may contribute to disparities in health.

Objectives: To determine if perceived racism in healthcare differs by race among patients with SLE and to evaluate its contribution to racial disparities in SLErelated outcomes.

Methods: 163 African-American (AA) and 180 white (WH) patients with SLE were enrolled. Structured interviews and chart reviews were done to determine perceptions of racism, SLE-related outcomes (Systemic Lupus International Collaborating Clinics (SLICC) Damage Index, SLE Disease Activity, Center for Epidemiologic Studies-Depression (CES-D)), and other variables that may affect perceptions of racism. Serial hierarchical multivariable logistic regression models were conducted. Race-stratified analyses were also performed.

Results: $56.0 \%$ of AA patients compared with $32.8 \%$ of WH patients had high perceptions of discrimination in healthcare $(p<0.001)$. This difference remained $(0 R$ $4.75(95 \% \mathrm{Cl} 2.41$ to 8.68$)$ ) after adjustment for background, identity and healthcare experiences. Female gender $(p=0.012)$ and lower trust in physicians $(p<0.001)$ were also associated with high perceived racism. The odds of having greater disease damage (SLICC damage index $\geq 2$ ) were higher in AA patients than in WH patients (crude OR $1.55(95 \% \mathrm{Cl} 1.01$ to 2.38)). The odds of having moderate to severe depression (CES-D $\geq 17$ ) were also higher in $A A$ patients than in WH patients (crude OR 1.94 (95\% Cl 1.26 to 2.98)). When adjusted for sociodemographic and clinical characteristics, racial disparities in disease damage and depression were no longer significant. Among AA patients, higher perceived racism was associated with having moderate to severe depression (adjusted OR $1.23(95 \% \mathrm{Cl} 1.05$ to 1.43$)$ ) even after adjusting for sociodemographic and clinical variables.

Conclusions: Perceptions of racism in healthcare were more common in AA patients than in WH patients with SLE and were associated with depression. Interventions aimed at modifiable factors (eg, trust in providers) may reduce higher perceptions of racebased discrimination in SLE.

\section{KEY MESSAGES}

- This is the first study to demonstrate that African-Americans with systemic lupus erythematosus (SLE) are more likely to perceive racism in the medical setting than white patients with SLE.

- Factors associated with high perceived racism in patients with SLE include African-American race, female gender and low trust in physicians.

- Among patients with SLE, AA patients have more disease-related organ damage and greater levels of depression than WH patients.

- Among African-Americans, higher perceived racism is significantly associated with greater levels of depression in SLE.

\section{INTRODUCTION}

Racial disparities exist in the prevalence, disease course and outcomes of patients with systemic lupus erythematosus (SLE). African-Americans (AAs) have a 2.5-3.5-fold higher prevalence of SLE compared with white (WH) people. ${ }^{1}$ They are also more likely to have depression, higher disease activity and higher SLE-related damage accrual than WH patients. ${ }^{2-4}$ Mortality rates are also markedly higher among AA patients than WH patients with SLE. ${ }^{6}$ Our understanding of the reasons underlying racial disparities in health outcomes in SLE is incomplete, however. Racial discrimination is a potential, yet unexplored, contributor of disparities in SLE outcomes.

Racial discrimination refers to the differential treatment on the basis of race, or inadequately justified factors other than race, that disadvantages a racial group. ${ }^{7}$ It can affect health through exposure, susceptibility, and responses to economic and social deprivation; toxic or hazardous conditions; socially inflicted trauma; or inadequate healthcare. ${ }^{8}$ From another perspective, discrimination can enhance exposure to noxious chemical, 
biological and psychosocial insults, all of which can affect health at multiple levels. ${ }^{8}$

Perceived discrimination is the term used when discrimination is believed to have occurred in the absence of definitive evidence. ${ }^{7}$ It has been studied in healthcare settings, and variation exists in how it is measured. ${ }^{8}$ Studies have measured perceived discrimination in healthcare by assessing personal experiences (ie, personal discrimination) and by assessing general perceptions that racism exists in the healthcare system (ie, perceived racism).$^{9-12}$ Measures of perceived racism ask patients about their general awareness of and views about racism, regardless of their personal experiences. ${ }^{9}$ Hammond's conceptual model suggests that perceived racism in healthcare is informed by several factors, including patient background, identity/socialisation factors and healthcare experiences (see online supplement 1$).{ }^{13}$ While these factors may directly affect outcomes, their impact may also be mediated by the psychophysiological effects of perceived racism. ${ }^{13}$

Evidence shows that AA patients are more likely than WH patients to perceive personal discrimination and general racism in the healthcare system, with differences typically being larger for measures of perceived racism in general. ${ }^{9}{ }^{10} 14$ Greater perceived racism among AA patients than $\mathrm{WH}$ patients has been reported in patients with diabetes, heart disease and other diseases. ${ }^{9-12}$ In contrast to these chronic diseases, SLE is a multisystem autoimmune disease, is often diagnosed at a younger age, is more common in women, and is more commonly seen in racial/ethnic minorities. ${ }^{1} 2$ It is unknown whether racial differences in perceived racism in healthcare exist among patients with lupus.

Perceived racism and/or discrimination can contribute to persistent social disparities in health. ${ }^{8}{ }^{15}$ Studies have shown that higher levels of perceived racism and discrimination are associated with poorer mental health status and physical functioning. ${ }^{12}{ }^{15} 16$ People who perceive racism are less likely to be satisfied with their care, and are more likely to have medical mistrust. ${ }^{10}{ }^{13}$ People who perceive discrimination are more likely to use tobacco and alcohol, and are less likely to seek medical treatment and preventive services. ${ }^{12} 1718$ They also have a higher risk of coronary artery obstruction and have higher levels of inflammation. ${ }^{19}{ }^{20}$ SLE is linked with greater levels of systemic inflammation. ${ }^{21}$ Whether higher perceived racism is associated with worse SLE outcomes has not been previously examined. It is also unclear whether perceived racism in healthcare contributes to racial disparities in lupus-related health outcomes.

The primary objective of this study was to determine whether there are differences in perceived racism in the healthcare setting between $\mathrm{AA}$ and $\mathrm{WH}$ patients with SLE. A second objective was to determine whether racial differences in the perception of racism persist in the context of a broad range of factors that could also influence perceived racism. Finally, we sought to examine if perceived racism in the healthcare system is associated with racial disparities in SLE-related health outcomes.

\section{MATERIALS AND METHODS}

Patients were recruited from rheumatology clinics of two academic medical centres, University of Chicago and University of Pittsburgh. Adult patients with a SLE diagnosis who were managed at these clinics between November 2009 and August 2012 were considered for participation. Potentially eligible patients were approached by staff to undergo screening during clinic appointments. To be eligible, patients had to meet the American College of Rheumatology (ACR) criteria for SLE ( $\geq 4$ of 11 ), must be $\geq 18$ years of age, must have reported a race of non-Hispanic AA or non-Hispanic $\mathrm{WH}$, and must not have had moderate-severe cognitive dysfunction.

\section{Data collection}

Patients who were eligible and consented to participate completed a telephone survey regarding perceived racism in the medical setting, sociodemographic information, psychosocial characteristics, and attitudes and beliefs regarding their disease and their healthcare providers. They were required to complete the survey within 2-3 weeks after consenting to study participation. Patients' medical records were reviewed to determine SLE disease activity, disease-related organ damage and presence of clinical comorbidities based on data up to their last clinic appointment (ie, the appointment closest to the date of survey completion).

This study was part of a larger study on patient treatment preferences, and specific details on patients included in and excluded from the study were previously reported. ${ }^{22}$ Briefly, 473 patients were considered for participation in the parent study, 384 consented and 343 were included in the current analysis. Patients who were not successfully contacted by telephone or failed to answer $>50 \%$ of the survey questions were excluded from this particular analysis.

\section{Primary predictor variable}

Separate questions regarding ethnicity (Hispanic or non-Hispanic) and race (AA, $\mathrm{WH}$ ) were used to create the primary predictor variable of self-identified patient race (non-Hispanic AA or non-Hispanic WH).

\section{Perceived racism}

Patients' perceived racism in healthcare was assessed using a measure developed by LaVeist et al. ${ }^{10}$ This measure assesses the extent to which patients have detected racism in doctors' offices and hospitals. It is a 4-item instrument, and survey participants were asked to report their degree of agreement with each item using a 5 -point Likert scale ( $1=$ strongly agree, $5=$ strongly disagree). A sample item determines agreement to the statement: 'Doctors treat African-American and white 
people the same'. The responses were summed (with a range of 4-20) to constitute the overall index score, and higher scores reflect more perceived racism. This measure has been shown to have strong construct validity and high internal reliability (Cronbach's $\alpha=0.82$ ). ${ }^{10} 23$ Our cohort's perceived racism scores had a bimodal distribution, and patients were grouped into those with high and low perceived racism, with high perceived racism defined as having an index score $>10$, the median index score. ${ }^{24}$

\section{Potential determinants of perceived racism}

The following variables were chosen based on Hammond's identified categories of variables that may impact people's perceptions of racism (see online supplement 1$).{ }^{13}$ Variables that could potentially affect perceived racism and the clinical outcomes based on studies of patients with lupus were measured and incorporated into the model. ${ }^{3} 425$

\section{Background information}

Sociodemographic characteristics included self-reported age, gender, education, household income, employment, medical insurance and marital status. Clinical features determined from chart review included disease duration, number of immunosuppressive medications used (past and present) and comorbidities. Disease duration was defined as the duration since the diagnosis of SLE until the interview appointment date. Comorbid conditions were weighted and summed using the Charlson Comorbidity Index. ${ }^{26}$

\section{Identity/socialisation characteristics}

Risk-taking propensity regarding health-related matters was determined using the domain-specific risk attitude scale (range: $10-50) .{ }^{27}$ Multidimensional health locus of control (HLC) was determined to measure the degree to which patients feel their own actions or that of others (eg, powerful others or chance alone) could affect their health (range: $6-36$, in each subscale) ${ }^{28}$

\section{Healthcare experiences}

Patients were asked the approximate month and year when they started seeing their current rheumatologist to calculate patient-provider relationship duration. Patient-reported physician participatory decision-making (PDM) style (range: 0-100; higher score indicates more participatory style) and trust in physicians in general (range: 11-55; higher score indicates greater trust) were also measured. ${ }^{29} 30$

\section{Clinical outcome variables}

Lupus disease activity was calculated using the SLE Disease Activity Index (SLEDAI) ${ }^{31}$ For this study, high disease activity was defined as a SLEDAI score $\geq 4$. We chose this score because it has been associated with the need to intensify therapy. ${ }^{32}$ Extent of disease organ damage was determined using the Systemic Lupus
International Collaborating Clinics (SLICC)/ACR Damage Index. ${ }^{33}$ For our study, high SLICC damage index score was defined as a score $\geq 2$ based on this score being associated with higher mortality in SLE. ${ }^{34}$ Level of depression was measured using the Center for Epidemiologic Studies Depression (CES-D) scale (range: 1-53). ${ }^{35}$ CES-D scores $\geq 17$ were considered indicative of moderate-severe depression. ${ }^{35}$

\section{Statistics}

Demographic, clinical and psychosocial characteristics were compared by race. Continuous variables were compared by two-sample $\mathrm{t}$ test or Wilcoxon rank sum test. Categorical variables were compared by Pearson's $\chi^{2}$ test or Fisher's exact test. In the same manner, these characteristics were contrasted by level of perceived racism in healthcare.

Logistic regression models were performed to evaluate the relationship between perceived racism and race, adjusted for covariates. Perceived racism status (high vs low) was the dependent variable in these models. The initial model in these analyses included only race as the independent variable. Patient characteristics and beliefs that may influence the relationship between perceived racism and race, based on bivariate analyses and Hammond's conceptual model, ${ }^{13}$ were then added in a hierarchical fashion to subsequent models. Only variables that were statistically significantly associated with perceived racism based on bivariate analyses $(p \leq 0.05)$ were considered for inclusion.

A series of hierarchical logistic regression analyses were also conducted to examine the effect of race on each clinical outcome of interest, unadjusted and adjusted for relevant sociodemographic and clinical characteristics. $^{3} 425$ The categorised SLEDAI (high vs low), SLICC Damage Index (high vs low) or CES-D (none-mild vs moderate-severe) were the dependent variables in these models. To determine whether perceived racism was a significant mediator of racial differences in each clinical outcome, we repeated the analyses described above, adding perceived racism as an additional predictor. A greater than $10 \%$ change in significant OR values between race and the outcome after the addition of perceived racism suggested mediation. ${ }^{36}$ Performing linear regression analyses, while treating each outcome variable as a continuous variable, yielded very similar results to the logistic regression models (data not shown).

Unadjusted and adjusted logistic regression models were also created to examine the effect of perceived racism on each clinical outcome variable stratified by race. To further explore the effect of perceived racism on clinical outcomes among AA patients, additional models were conducted limited to AA patients, further stratified by several socioeconomic factors, including income, education, marital status and medical insurance. Statistical significance was set with an $\alpha$ level of 0.05 . 


\section{RESULTS}

The sample included $180 \mathrm{WH}$ and 163 AA patients with SLE. WH and AA patients with SLE differed on many sociodemographic and clinical characteristics (table 1). AA patients, compared with $\mathrm{WH}$ patients, were younger $(\mathrm{p}<0.001)$, had less education $(\mathrm{p}=0.004)$ and were less likely to be married $(\mathrm{p}<0.001)$. They also reported lower income and were less likely to have private medical insurance (both $\mathrm{p}<0.001$ ).

Compared with WH patients with SLE, AA patients with SLE were more likely to believe that their health outcomes are controlled by their actions $(\mathrm{p}=0.004)$ and by chance alone $(\mathrm{p}=0.024)$. AA patients were also less likely to report that physicians would involve them in the medical decision-making process $(\mathrm{p}<0.001)$.

SLEDAI score did not differ by race. Compared with WH patients, AA patients had higher SLICC Damage Index $(p=0.010)$ and CES-D scores $(p=0.001)$.

\section{Perceptions of racism in SLE: bivariate analyses}

Approximately $56.0 \%$ of AA patients, compared with $32.8 \%$ of $\mathrm{WH}$ patients, had high perceived racism in healthcare score (crude OR, 2.59 (95\% CI 1.67 to 4.02), $\mathrm{p}<0.001)$. Online supplement 2 shows unadjusted relationships between patient characteristics and perceived racism. High perceived racism was more commonly seen in patients recruited from Chicago $(\mathrm{p}=0.013)$, among female patients with SLE $(\mathrm{p}=0.014)$ and among those with more than a high school graduate degree $(\mathrm{p}<0.001)$. It was also associated with having a lower Internal HLG score $(\mathrm{p}=0.041)$ and a lower Powerful others HLC score $(\mathrm{p}=0.037)$. Patients with high perceived racism had less trust in physicians $(p<0.001)$ and rated their physicians as having lower PDM styles $(\mathrm{p}=0.016)$.

\section{Perceived racial discrimination and race: multivariable} analyses

The odds of having high perceived racism were higher among AA patients compared with WH patients in the unadjusted model (table 2, Model 1). After adjustment for recruitment site, gender and education, this OR increased and remained statistically significant (table 2, Model 2; adjusted OR 3.00 (95\% CI 1.80 to 5.03)). This OR did not appreciably change when further adjusted for HLC-Internal score and HLC-Powerful others score (table 2, Model 3). After further adjustment with trust in physicians, this OR increased even further (table 2, Model 4; adjusted OR 4.70 (95\% CI 2.50 to 8.82)). In the final model, African-American race $(p<0.001)$, female gender $(\mathrm{p}=0.013)$ and low trust in physicians $(\mathrm{p}<0.001)$ were all independently associated with having high perceived racism (table 2, Model 4). The determinants of perceived racism by level of depression (nonemild vs moderate-severe) were also analysed. Determinants did not differ by level of depression (data not shown).

\section{Race and clinical outcomes}

We did not find a significant association between race and the odds of having a high SLEDAI score in the unadjusted model (table 3; crude OR 1.06 (95\% CI 0.69 to 1.62)). When adjusted for age, medical insurance, marital status and internal HLC, the OR remained statistically non-significant $(p=0.575)$. After further adjustment for perceived racism, the OR did not significantly change ( $p=0.743)$.

In contrast, AA patients with SLE had higher odds of having a high SLICC Damage Index score than WH patients with SLE in the unadjusted model (table 3; crude OR 1.55 (95\% CI 1.01 to 2.38)). When adjusted for age, gender, education, income, medical insurance, marital status and SLE duration, this OR increased (table 3; crude OR 2.02 (95\% CI 0.94 to 4.34)) but was no longer statistically significant $(\mathrm{p}=0.073)$. Further adjustment for perceived racism did not lead to a significant change in OR $(\mathrm{p}=0.071)$.

AA patients also had higher odds of having moderatesevere depression compared with $\mathrm{WH}$ patients in the unadjusted model (table 3; crude OR 1.94 (95\% CI 1.26 to 2.98)). However, this racial difference was no longer significant after adjusting for age, income, education, marital status, SLE duration and SLEDAI score $(p=0.639)$. The OR remained non-significant after further adjustment for perceived racism $(p=0.928)$.

\section{Perceived racism and outcomes: African-Americans}

Perceived racism was not significantly associated with either SLEDAI or SLICC Damage Index score among $\mathrm{AA}$ and $\mathrm{WH}$ patients (table 4). It was also not significantly associated with having moderate-severe depression among WH patients. Among AA patients, perceived racism was significantly associated with having moderatesevere depression even after adjustment for age, income, education, marital status, SLE duration and SLEDAI score (table 4; adjusted OR 1.23 (95\% CI 1.05 to 1.43). The relationship between perceived racism and having moderate-severe depression among AA patients, stratified by several different socioeconomic factors are presented in table 5. In sum, this relationship remained statistically significant in unadjusted and adjusted models among AA patients with SLE with a household income of $\leq \$ 30000 /$ year, with more than a high school education, who are not currently married, and with private medical insurance.

\section{DISCUSSION}

Our study is the first to demonstrate that, among patients with SLE, AA patients were more likely than WH patients to perceive racism in the healthcare setting. This difference in perceived racism remained significant despite controlling for patient background information, identity traits and healthcare experiences. Besides AA race, female gender and lower trust in physicians were also significant predictors of high perceived racism. We 
Table 1 Characteristics of White and African-American patients with SLE

\begin{tabular}{|c|c|c|c|}
\hline Characteristic & $\begin{array}{l}\text { White } \\
\mathrm{n}=180\end{array}$ & $\begin{array}{l}\text { African-American } \\
n=163\end{array}$ & p Value* \\
\hline \multicolumn{3}{|l|}{ Recruitment site, $\mathrm{n}(\%)$} & $<0.001$ \\
\hline U Chicago & $61(33.9)$ & $121(74.2)$ & \\
\hline U Pittsburgh & $119(66.1)$ & $42(25.8)$ & \\
\hline Age, mean $\pm S D$ years & $46.9 \pm 12.8$ & $41.9 \pm 13.0$ & $<0.001$ \\
\hline Gender, $\mathrm{n}(\%)$ female & $168(93.3)$ & $153(93.9)$ & 0.841 \\
\hline \multicolumn{3}{|l|}{ Education, $\mathrm{n}(\%)$} & 0.004 \\
\hline Less than HS graduate & $2(1.1)$ & $14(8.6)$ & \\
\hline HS graduate & $35(19.4)$ & $40(24.5)$ & \\
\hline More than $\mathrm{HS}$ graduate & $143(79.4)$ & $109(66.9)$ & \\
\hline \multicolumn{3}{|l|}{ Income, n (\%) } & $<0.001$ \\
\hline$<\$ 10000$ & $15(8.5)$ & $53(32.9)$ & \\
\hline$\$ 10001-30000$ & $26(14.7)$ & $47(29.2)$ & \\
\hline$\$ 30001-50000$ & $25(14.1)$ & $31(19.3)$ & \\
\hline$>\$ 50000$ & $106(59.9)$ & $30(18.6)$ & \\
\hline Employed, n (\%) & $95(52.8)$ & 64 (39.3) & 0.024 \\
\hline With private medical insurance, $\mathrm{n}(\%)$ & $154(85.6)$ & $62(38.0)$ & $<0.001$ \\
\hline Marital status, $\mathrm{n}(\%)$ married & $117(65.0)$ & $45(27.6)$ & $<0.001$ \\
\hline SLE disease duration, mean $\pm S D$ months & $151.1 \pm 128.6$ & $135.3 \pm 106.9$ & 0.221 \\
\hline \multicolumn{3}{|l|}{ \# Immunosuppressive drugs† used in the past, $\mathrm{n}(\%)$} & 0.040 \\
\hline 0 & $96(53.3)$ & $62(38.0)$ & \\
\hline 1 & $32(17.8)$ & $48(29.5)$ & \\
\hline 2 & 27 (15.0) & $31(19.0)$ & \\
\hline 3 & $14(7.8)$ & $11(6.8)$ & \\
\hline$\geq 4$ & $11(6.1)$ & $11(6.8)$ & \\
\hline \multicolumn{3}{|l|}{ \# Immunosuppressive drugs† currently used, n (\%) } & 0.400 \\
\hline 0 & $12(6.7)$ & $9(5.5)$ & \\
\hline 1 & $94(52.2)$ & $80(49.1)$ & \\
\hline$\geq 2$ & $74(41.1)$ & $74(45.4)$ & \\
\hline Charlson Comorbidity Index, mean \pm SD & $1.9 \pm 1.2$ & $2.4 \pm 1.4$ & 0.005 \\
\hline DOSPERT, mean \pm SD & $16.7 \pm 4.2$ & $16.9 \pm 5.1$ & 0.611 \\
\hline \multicolumn{4}{|l|}{ Health locus of control, mean $\pm S D$} \\
\hline Internal & $24.0 \pm 4.9$ & $25.6 \pm 5.3$ & 0.004 \\
\hline Chance & $17.6 \pm 5.1$ & $19.0 \pm 6.1$ & 0.024 \\
\hline Powerful others & $24.2 \pm 9.0$ & $24.9 \pm 5.4$ & 0.381 \\
\hline Physician-patient relation duration, mean $\pm S D$ years & $4.3 \pm 4.2$ & $6.2 \pm 5.7$ & $<0.001$ \\
\hline Duration of clinic follow-up, mean $\pm S D$ years & $7.7 \pm 7.5$ & $8.0 \pm 6.1$ & 0.603 \\
\hline Physician's PDM style, mean \pm SD & $75.4 \pm 22.2$ & $66.1 \pm 26.1$ & $<0.001$ \\
\hline Trust in physicians, mean $\pm S D$ & $38.5 \pm 8.5$ & $38.9 \pm 7.8$ & 0.690 \\
\hline SLEDAI, mean \pm SD & $3.21 \pm 2.8$ & $3.6 \pm 3.7$ & 0.274 \\
\hline SLICC Damage Index, mean \pm SD & $1.5 \pm 2.0$ & $2.1 \pm 2.1$ & 0.010 \\
\hline CES-D, mean \pm SD & $15.9 \pm 11.6$ & $20.2 \pm 12.7$ & 0.001 \\
\hline Perceived racism, median $\pm I Q R$ & $9.0 \pm 4.0$ & $11.0 \pm 5.0$ & $<0.0001$ \\
\hline \multicolumn{4}{|c|}{$\begin{array}{l}\text { *Significance level of the } \chi^{2} \text { statistic (or Wilcoxon's rank-sum test) for categorical variables and two-tailed t test for continuous variables. } \\
\text { tDrugs: azathioprine, belimumab, chloroquine, cyclophosphamide, cyclosporine, dapsone, hydroxychloroquine, quinacrine, leflunomide, } \\
\text { methotrexate, mycophenolate mofetil, rituximab, sulfasalazine, tacrolimus. } \\
\text { Statistically significant p-Values highlighted in bold. } \\
\text { CES-D, Center for Epidemiologic Studies Depression Scale; DOSPERT, domain-specific risk attitude scale; HS, high school; PDM, } \\
\text { participatory decision-making; SLE, systemic lupus erythematosus; SLEDAI, Systemic Lupus Erythematosus Disease Activity Index; SLICC, } \\
\text { Systemic Lupus International Collaborating Clinics. }\end{array}$} \\
\hline
\end{tabular}

also demonstrated racial disparities in SLE-related disease outcomes, with AA patients having more SLE-associated organ damage and depression than WH patients in unadjusted analyses. However, after further adjustment for relevant sociodemographic and clinical variables, racial disparities in SLE outcomes were no longer significant. Finally, we found a significant relationship between perceived racism and depression among AA patients with SLE.

Determinants of perceived racism in healthcare

Consistent with other studies of racial discrimination in healthcare, perceived racism was more prevalent among AA patients than WH patients in our study of patients 
Table 2 Logistic regression models of high perceived racism, with serial addition of background, identity and healthcare experiences

\begin{tabular}{|c|c|c|c|c|}
\hline Variable, OR (95\% Cl) & Model 1 & Model 2 & Model 3 & Model 4‡ \\
\hline African-American race & $2.59(1.67 \text { to } 4.02)^{*}$ & $3.00(1.80 \text { to } 5.03)^{*}$ & $3.40(1.99 \text { to } 5.80)^{*}$ & $4.70(2.50 \text { to } 8.82)^{\star}$ \\
\hline \multicolumn{5}{|l|}{ Recruitment site } \\
\hline$U$ of Chicago & & 1.00 & 1.00 & 1.00 \\
\hline $\mathrm{U}$ of Pittsburgh & & $0.74(0.45$ to 1.23$)$ & $0.72(0.43$ to 1.19$)$ & $0.82(0.46$ to 1.48$)$ \\
\hline \multicolumn{5}{|l|}{ Gender } \\
\hline Female & & 1.00 & 1.00 & 1.00 \\
\hline Male & & $0.25(0.08$ to 0.80$) \dagger$ & $0.26(0.08$ to 0.86$) \dagger$ & $0.19(0.05$ to 0.70$) \dagger$ \\
\hline \multicolumn{5}{|l|}{ Education } \\
\hline Less than HS & & 1.00 & 1.00 & 1.00 \\
\hline HS & & $1.02(0.30$ to 3.45$)$ & $0.96(0.28$ to 3.37$)$ & $0.76(0.19$ to 3.06$)$ \\
\hline More than $\mathrm{HS}$ & & $4.11(1.32$ to 12.86$) \dagger$ & $3.46(1.07$ to 11.22$) t$ & 2.35 (0.64 to 8.69$)$ \\
\hline High locus of control-internal§ & & & $0.77(0.47$ to 1.26$)$ & $0.93(0.54$ to 1.61$)$ \\
\hline $\begin{array}{l}\text { High locus of control-powerful } \\
\text { others } \ddagger\end{array}$ & & & $0.50(0.30$ to 0.83$) \dagger$ & $0.82(0.46$ to 1.45$)$ \\
\hline Trust in physicians & & & & $0.85(0.82 \text { to } 0.89)^{\star}$ \\
\hline
\end{tabular}

with SLE. This racial difference in perceived racism may be due to variation in experiences. Greater perceived racism may also be grounded in real-life experiences, more so in AA than in WH patients. AA patients may have had more personal experiences to draw from whereas $\mathrm{WH}$ patients may be basing their ratings based on what they had heard from others. It is also possible that $\mathrm{WH}$ patients do not think that there is validity to the claim of discrimination in care; responses of $\mathrm{WH}$ patients to the perceived racism statements may be based more on a strong personal belief that racial discrimination in the healthcare system is rare than on actual experiences. The proportion of $\mathrm{WH}$ and $\mathrm{AA}$ patients reporting high levels of perceived racism is similar to what others have found. ${ }^{9}{ }^{10}$ Rates of perceived racism are also higher when assessed using a measure of general perceptions of racism, such as the measure used in this study, than when using a measure of personal experiences of discrimination..$^{9}$ Regardless, in studies of multiple clinical patient populations, AA patients more frequently report race-based discrimination, either based on personal healthcare experiences or in the healthcare system in general compared with WH patients. ${ }^{9-12}$

Table 3 Race in relation to clinical outcome variables*

\begin{tabular}{|c|c|c|}
\hline & OR & $95 \% \mathrm{Cl}$ \\
\hline \multicolumn{3}{|l|}{ SLE Disease Activity (SLEDAI score $\geq 4$ ) } \\
\hline AA race (crude) & 1.06 & 0.69 to 1.62 \\
\hline $\begin{array}{l}\text { AA race (adjusted for age, medical insurance, } \\
\text { marital status, internal HLC) }\end{array}$ & 0.86 & 0.52 to 1.44 \\
\hline AA race (further adjusted for perceived racism) & 0.91 & 0.53 to 1.57 \\
\hline \multicolumn{3}{|l|}{ SLE Damage Index (SLICC score $\geq 2$ ) } \\
\hline AA race (crude) & 1.55 & 1.01 to $2.38 \dagger$ \\
\hline $\begin{array}{l}\text { AA race (adjusted for age, gender, education, income, } \\
\text { medical insurance, marital status, SLE duration) }\end{array}$ & 2.02 & 0.94 to 4.34 \\
\hline AA race (further adjusted for perceived racism) & 2.14 & 0.94 to 4.88 \\
\hline \multicolumn{3}{|l|}{ Depression (CES-D Score $\geq 17$ ) } \\
\hline AA race (crude) & 1.94 & 1.26 to $2.98 \dagger$ \\
\hline $\begin{array}{l}\text { AA race (adjusted for age, income, education, } \\
\text { marital status, SLE duration, SLEDAI) }\end{array}$ & 1.16 & 0.62 to 2.20 \\
\hline AA race (further adjusted for perceived racism) & 0.97 & 0.49 to 1.92 \\
\hline
\end{tabular}

*Based on separate logistic regression models for each outcome.

$t \mathrm{p}<0.05$.

AA, African-American; CES-D, Center for Epidemiologic Studies Depression Scale; HLC, health locus of control; SLE, systemic lupus erythematosus; SLEDAI, Systemic Lupus Erythematosus Disease Activity Index; SLICC, Systemic Lupus International Collaborating Clinics. 
Table 4 Perceived racism in relation to SLE-related clinical outcomes, by race*

OR

$95 \% \mathrm{Cl}$

\begin{tabular}{|c|c|c|}
\hline \multicolumn{3}{|l|}{ AFRICAN-AMERICAN ( $n=163)$} \\
\hline \multicolumn{3}{|l|}{ SLE Disease Activity (SLEDAI Score $\geq 4$ ) } \\
\hline Perceived racism (crude) & 1.01 & 0.93 to 1.11 \\
\hline Perceived racism (adjusted for age, medical insurance, marital status, internal HLC) & 1.03 & 0.94 to 1.15 \\
\hline \multicolumn{3}{|l|}{ SLE Damage Index (SLICC Score $\geq 2$ ) } \\
\hline Perceived racism (crude) & 1.02 & 0.93 to 1.12 \\
\hline $\begin{array}{l}\text { Perceived racism (adjusted for age, gender, education, income, } \\
\text { medical insurance, marital status, SLE duration) }\end{array}$ & 1.04 & 0.89 to 1.22 \\
\hline \multicolumn{3}{|l|}{ Depression (CES-D Score $\geq 17$ ) } \\
\hline Perceived racism (crude) & 1.10 & 1.00 to $1.21 \dagger$ \\
\hline $\begin{array}{l}\text { Perceived racism (adjusted for age, income, education, } \\
\text { marital status, SLE duration, SLEDAl) }\end{array}$ & 1.23 & 1.05 to $1.43 \dagger$ \\
\hline \multicolumn{3}{|l|}{ WHITE $(\mathrm{n}=180)$} \\
\hline \multicolumn{3}{|l|}{ SLE Disease Activity (SLEDAI Score $\geq 4$ ) } \\
\hline Perceived racism (crude) & 0.94 & 0.85 to 1.02 \\
\hline \multicolumn{2}{|l|}{ SLE Damage Index (SLICC Score $\geq 2$ ) } & 0.84 to 1.02 \\
\hline Perceived racism (crude) & 0.99 & 0.90 to 1.09 \\
\hline $\begin{array}{l}\text { Perceived racism (adjusted for age, gender, education, income, } \\
\text { medical insurance, marital status, SLE duration) }\end{array}$ & 0.94 & 0.82 to 1.08 \\
\hline \multicolumn{3}{|l|}{ Depression (CES-D Score $\geq 17$ ) } \\
\hline Perceived racism (crude) & 0.99 & 0.90 to 1.08 \\
\hline $\begin{array}{l}\text { Perceived racism (adjusted for age, income, education, } \\
\text { marital status, SLE duration, SLEDAl) }\end{array}$ & 0.99 & 0.88 to 1.13 \\
\hline
\end{tabular}

*Based on separate logistic regression models for each outcome by patient race.

$+\mathrm{p}<0.05$.

CES-D, Center for Epidemiologic Studies Depression Scale; HLC, health locus of control; SLE, systemic lupus erythematosus; SLEDAI,

Systemic Lupus Erythematosus Disease Activity Index; SLICC, Systemic Lupus International Collaborating Clinics.

In parallel, having higher trust in physicians was independently associated with less perceived racism in healthcare in our cohort of patients. Other studies have shown a similar inverse relationship between trust in providers and perceived racial discrimination in other patient groups. ${ }^{10} 133738$ These studies primarily treated low levels of trust in providers as consequences of perceived discrimination. At the same time, most of the studies are cross-sectional in design, leaving open the possibility that perceptions of discrimination are a consequence of extent of trust in physicians. Regardless, trust in providers is a modifiable factor that can be targeted to reduce high perceived racism in healthcare. Moreover, AA patients with SLE are more commonly classified as non-adherent to medical recommendations than WH patients with SLE, and this limitation in adherence may be related to low trust in providers. ${ }^{39}$

Our study also demonstrates that racism was more often perceived by women compared with men with SLE. Other studies examining self-reported racism in non-healthcare settings such as the workplace and during encounters with law enforcement have found that men report a higher prevalence than women. ${ }^{40} 41$ During healthcare encounters, though, racial discrimination is more frequently reported by women than by men. ${ }^{11}{ }^{42}$ As we have a limited number of men in the current study due to expected female predominance in SLE, further investigation in this matter is warranted.
We found that perceived racism was also more common among patients with SLE with higher education, consistent with what others have found. ${ }^{41}$ It has been postulated that those in a higher socioeconomic position are more likely to be exposed to situations in which they experience discrimination or are more aware of subtle forms of discrimination. ${ }^{12}$ Belief that powerful others (eg, providers) could significantly affect health outcomes was related to having lower perceived racism in our study. Patients who have this belief may be highly reliant on providers to make medical decisions for them. ${ }^{43}$ In turn, they may be less likely to believe that providers and the healthcare system are highly biased.

Nevertheless, our study suggests that patient background, identity/socialisation characteristics and reported healthcare experiences do not fully explain racial disparities in perceptions of racism in healthcare. This is consistent with another study of 6299 adults in which racial differences in patient perceptions of healthcare system-wide bias persisted after controlling for demographics, source of care and patient-physician communication variables. ${ }^{44}$ As both studies only measured patient-level characteristics, there is a possibility that unmeasured provider, healthcare system and other environmental variables are the appropriate explanatory variables. For example, limited medical resources and unconscious bias among providers have been associated with racial differences in reported perceptions. ${ }^{11} 44$ 
Table 5 Associations between perceived racism score and having moderate-severe depression (CES-D score $\geq 17$ ) among African-Americans by income, education, marital status and medical insurance*

OR $(95 \% \mathrm{Cl})$

Annual household income $\leq \$ 30000 /$ year $(n=100)$

Perceived racism (crude)

Perceived racism (adjusted for age, education, marital status, SLE duration, SLEDAI)

$1.20(1.05$ to 1.38$) \dagger$

$1.26(1.06$ to 1.51$) \dagger$

Annual household income $>\$ 30000 /$ year $(n=61)$

Perceived racism (crude)

Perceived racism (adjusted for age, education, marital status, SLE duration, SLEDAI)

1.07 (0.90 to 1.27$)$

$1.11(0.82$ to 1.49$)$

High school or less than high school graduate $(n=54)$

Perceived racism (crude)

Perceived racism (adjusted for age, income, marital status, SLE duration, SLEDAI)

1.09 (0.90 to 1.32$)$

$1.12(0.81$ to 1.52$)$

More than high school graduate $(n=109)$

Perceived racism (crude)

Perceived racism (adjusted for age, income, marital status, SLE duration, SLEDAI)

1.21 (1.06 to 1.37$) \dagger$

$1.26(1.04$ to 1.53$) \dagger$

Not currently married $(n=118)$

Perceived racism (crude)

Perceived racism (adjusted for age, education, income, SLE duration, SLEDAI)

$1.14(1.02$ to 1.27$) \dagger$

$1.22(1.04$ to 1.43$) \dagger$

Currently married $(n=45)$

Perceived racism (crude)

Perceived racism (adjusted for age, education, income, SLE duration, SLEDAI)

$1.00(0.81$ to 1.25$)$

1.47 (0.63 to 3.43$)$

Without private medical insurance $(n=101)$

Perceived racism (crude)

Perceived racism (adjusted for age, education, income, marital status, SLE duration, SLEDAI)

1.14 (1.00 to 1.29$)$

With private medical insurance $(n=62)$

Perceived racism (crude)

Perceived racism (adjusted for age, education, income, marital status, SLE duration, SLEDAI)

*Based on separate logistic regression models for each demographic category.

$+\mathrm{p}<0.05$.

CES-D, Center for Epidemiologic Studies Depression Scale; SLEDAI, Systemic Lupus Erythematosus Disease Activity Index.

\section{Racial disparities in SLE clinical outcomes}

We did not find race to be associated with SLE disease activity, a finding similarly found by Karlson et al. ${ }^{45}$ In contrast, AA race was significantly associated with having greater disease activity among patients in the Lupus in Minorities: Nature versus Nurture (LUMINA) cohort. ${ }^{2} 4$ The lack of association in our study may be due to participation bias. Patients with more severe disease may have been less inclined to participate in our survey. It is also possible that our measure of disease activity was not sufficiently sensitive to detect differences associated with race. We used the SLEDAI while the LUMINA studies used the Systemic Lupus Activity Measure-Revised (SLAM-R) to measure disease activity. While the SLAM-R is strongly correlated with the SLEDAI, it may more readily detect aspects of disease activity important to patients. ${ }^{46}$

We found AA race to be associated with higher SLE-related cumulative organ damage in unadjusted analyses, but this association did not persist after adjusting for sociodemographic factors and disease duration, consistent with prior studies. ${ }^{2}{ }^{3} 45$ Consequently, perceived racism was not found to be an important explanatory variable for racial differences in SLE organ damage. In Karlson et als study, ${ }^{45}$ cumulative organ damage was strongly associated with age and duration of disease, and weakly associated with lower caloric intake, occupational prestige and disease activity at diagnosis. In the LUMINA cohort, AA patients had higher damage index scores than WH patients. ${ }^{3}$ After adjusting for disease duration, though, AA race was no longer a significant predictor of SLE damage accrual. $^{3}$

A similar pattern was observed for depression in that AA participants were more likely to have moderatesevere depression compared with $\mathrm{WH}$ patients in unadjusted analyses but not after controlling for socioeconomic status, disease duration and disease activity. Racial differences in the prevalence/incidence rates of depression among patients with SLE have also been found by others, but not all. ${ }^{47}{ }^{48}$ Regardless, rates of certain depressive and anxiety disorders have been reported to be higher among AA patients than $\mathrm{WH}$ patients in other patient groups and have been accounted for by socioeconomic status differences. ${ }^{49}$ In SLE, higher disease activity may also increase vulnerability to depression. ${ }^{25}$

We also found an association between perceived racism in healthcare and depression among AA patients with SLE. This association was specifically relevant among AA patients with low income, with greater educational attainment, who are not married and with private health insurance. Indeed, almost without exception, studies of discrimination and mental health find that higher levels of experienced discrimination are associated with poorer 
mental health status. ${ }^{15}$ However, we did not find an association between perceived racism and either SLEDAI or SLICC damage index. Indeed, not all studies have found a negative impact of perceived discrimination on health. ${ }^{11}$ In one particular cross-sectional study, AA patients with spinal cord injuries who reported more discrimination also reported better occupational functioning. ${ }^{50}$

Limitations of the study should be noted. First, the study is cross-sectional in design. While we propose that general perceptions of racial discrimination may lead to poorer mental health, it is also possible that these perceptions are a consequence of mental health status. Hence, it is noteworthy that a few prospective studies have shown evidence that perceived discrimination is associated with subsequent reports of depression. ${ }^{15}$ Second, our measure of perceived racism in healthcare has limitations. It assesses general perceptions of racism but not personal experiences with discrimination. Personal experiences of racial discrimination may be more strongly tied to poorer health outcomes than general perceptions of discrimination. In a comparison of the different measures of perceived discrimination in patients with diabetes, the measures had variable associations with perceptions of care but not with actual receipt of recommended screenings for disease complications. ${ }^{9}$ Our measure of perceived racism is also based on patient report which is susceptible to recall bias. Measuring the impact of actual occurrence of discriminatory events, though, is impractical and may not be possible. Finally, the extent to which the results of the study can be generalised to other racial/ethnic minority groups is unclear. Nevertheless, in the USA, AA patients most frequently report race/ethnicity-based discrimination during healthcare encounters, and are most likely to have negative consequences from it. ${ }^{11}$

Despite these limitations, this study advances our understanding of the correlates of perceived racism in healthcare by demonstrating that AA race, female gender and lower level of trust in providers are associated with higher perceived racism in healthcare for patients with SLE. It also shows that racial disparities in the perceptions of racism in healthcare persist despite accounting for patient background, identity/socialisation characteristics and healthcare experiences. Moreover, the study demonstrates that higher perceptions of racism are associated with more depression in patients with SLE, which disproportionately impacts AA patients. Future research should explore the inverse relationship between trust in physicians and perceived racism to determine whether low levels of trust are a cause or consequence of perceived racism and whether interventions to enhance physicianpatient trust can reduce perceived racism and lead to improved health outcomes.

Acknowledgement The authors thank the patients who participated in the study.

Contributors All authors were involved in drafting the article or revising it critically for important intellectual content, and all authors approved the final version to be published. ERV, LRMH, TOU, CMM and CKK contributed to the study concept and design. ERV, TOU and KL assisted with the acquisition of data. EV, LH, CMM, KPL and CKK contributed to the analysis and interpretation of data.

Funding ERV was supported by the Rheumatology Research Foundation. Competing interests None declared.

Ethics approval University of Chicago and University of Pittsburgh Institutional Review Boards.

Provenance and peer review Not commissioned; externally peer reviewed.

Data sharing statement No additional data are available.

Open Access This is an Open Access article distributed in accordance with the Creative Commons Attribution Non Commercial (CC BY-NC 4.0) license, which permits others to distribute, remix, adapt, build upon this work noncommercially, and license their derivative works on different terms, provided the original work is properly cited and the use is non-commercial. See: http:// creativecommons.org/licenses/by-nc/4.0/

\section{REFERENCES}

1. Chakravarty EF, Bush TM, Manzi S, et al. Prevalence of adult systemic lupus erythematosus in California and Pennsylvania in 2000: estimates obtained using hospitalization data. Arthritis Rheum 2007:56:2092-4.

2. Fernandez M, Alarcon GS, Calvo-Alen J, et al. A multiethnic, multicenter cohort of patients with systemic lupus erythematosus (SLE) as a model for the study of ethnic disparities in SLE. Arthritis Rheum 2007;57:576-84.

3. Alarcon GS, McGwin G Jr, Bartolucci AA, et al. Systemic lupus erythematosus in three ethnic groups. IX. Differences in damage accrual. Arthritis Rheum 2001;44:2797-806.

4. Alarcon GS, Calvo-Alen J, McGwin G, Jr., et al. Systemic lupus erythematosus in a multiethnic cohort: LUMINA XXXV. Predictive factors of high disease activity over time. Ann Rheum Dis 2006;65:1168-74.

5. Ward MM, Pyun E, Studenski S. Long-term survival in systemic lupus erythematosus. Patient characteristics associated with poorer outcomes. Arthritis Rheum 1995;38:274-83.

6. Centers for Disease Control and Prevention (CDC). Trends in deaths from systemic lupus erythematosus-United States, 1979-1998. MMWR Morb Mortal Wkly Rep 2002;51:371-4.

7. Blank RM, Dabady M, Citro CF, eds. Measuring racial discrimination Panel on methods for assessing discrimination. committee on National Statistics, Division of Behavioral and Social Sciences and Education. National Research Council. Washington DC: National Academies Press, 2004.

8. Krieger N. Discrimination and health. In: Berkman LF, Kawachi I, eds. Social epidemiology. New York, NY: Oxford University Press, Inc., 2000:36-75.

9. Hausmann LR, Kressin NR, Hanusa BH, et al. Perceived racial discrimination in health care and its association with patients' healthcare experiences: does the measure matter? Ethn Dis 2010;20:40-7.

10. LaVeist TA, Nickerson KJ, Bowie JV. Attitudes about racism, medical mistrust, and satisfaction with care among African American and white cardiac patients. Med Care Res Rev 2000;57(Suppl 1): $146-61$.

11. Shavers VL, Fagan $P$, Jones $\mathrm{D}$, et al. The state of research on racial/ethnic discrimination in the receipt of health care. Am J Public Health 2012;102:953-66.

12. Borrell LN, Jacobs DR, Jr., Williams DR, et al. Self-reported racial discrimination and substance use in the Coronary Artery Risk Development in Adults Study. Am J Epidemiol 2007;166:1068-79.

13. Hammond WP. Psychosocial correlates of medical mistrust among African American men. Am J Community Psychol 2010;45:87-106.

14. Lillie-Blanton M, Brodie M, Rowland D, et al. Race, ethnicity, and the health care system: public perceptions and experiences. Med Care Res Rev 2000;57(Suppl 1):218-35.

15. Williams DR, Mohammed SA. Discrimination and racial disparities in health: evidence and needed research. $J$ Behav Med 2009;32:20-47.

16. Hausmann LR, Jeong $\mathrm{K}$, Bost JE, et al. Perceived discrimination in health care and health status in a racially diverse sample. Med Care 2008;46:905-14.

17. Trivedi AN, Ayanian JZ. Perceived discrimination and use of preventive health services. J Gen Intern Med 2006;21:553-8. 
18. Casagrande SS, Gary TL, LaVeist TA, et al. Perceived discrimination and adherence to medical care in a racially integrated community. $J$ Gen Intern Med 2007;22:389-95.

19. Beatty DL, Matthews KA, Bromberger JT, et al. Everyday discrimination prospectively predicts inflammation across 7-years in racially diverse midlife women: Study of Women's Health Across the Nation. J Soc Issues 2014;70:298-314.

20. Ayotte BJ, Hausmann LR, Whittle J, et al. The relationship between perceived discrimination and coronary artery obstruction. Am Heart $J$ 2012;163:677-83.

21. Vila LM, Alarcon GS, McGwin G, Jr., et al. Systemic lupus erythematosus in a multiethnic cohort (LUMINA): XXIX. Elevation of erythrocyte sedimentation rate is associated with disease activity and damage accrual. $J$ Rheumatol 2005;32:2150-5.

22. Vina ER, Utset TO, Hannon MJ, et al. Racial differences in treatment preferences among lupus patients: a two-site study. Clin Exp Rheumatol 2014;32:680-8.

23. Vina ER, Masi CM, Green SL, et al. A study of racial/ethnic differences in treatment preferences among lupus patients. Rheumatology (Oxford) 2012;51:1697-706.

24. Szklo M, Nieto FJ. Stratification and adjustment: multivariate analysis in epidemiology. In: Epidemiology, beyond the basics. Sudbury, Massachusetts: Jones and Bartlett Publishers, 2007:227-96.

25. Palagini L, Mosca M, Tani C, et al. Depression and systemic lupus erythematosus: a systematic review. Lupus 2013;22:409-16.

26. Charlson ME, Pompei P, Ales KL, et al. A new method of classifying prognostic comorbidity in longitudinal studies: development and validation. J Chronic Dis 1987;40:373-83.

27. Weber E, Blais A-R, Betz N. A domain-specific risk-attitude scale: measuring risk perceptions and risk behaviors. J Behav Decis Mak 2002;15:263-90.

28. Wallston KA, Wallston BS, DeVellis R. Development of the Multidimensional Health Locus of Control (MHLC) Scales. Health Educ Monogr 1978;6:160-70.

29. Kaplan SH, Gandek B, Greenfield S, et al. Patient and visit characteristics related to physicians' participatory decision-making style. Results from the Medical Outcomes Study. Med Care 1995;33:1176-87.

30. Hall MA, Camacho F, Dugan E, et al. Trust in the medical profession: conceptual and measurement issues. Health Serv Res 2002;37:1419-39.

31. Bombardier C, Gladman DD, Urowitz MB, et al. Derivation of the SLEDAI. A disease activity index for lupus patients. The Committee on Prognosis Studies in SLE. Arthritis Rheum 1992;35:630-40.

32. Yee CS, Farewell VT, Isenberg DA, et al. The use of Systemic Lupus Erythematosus Disease Activity Index-2000 to define active disease and minimal clinically meaningful change based on data from a large cohort of systemic lupus erythematosus patients. Rheumatology (Oxford) 2011;50:982-8.

33. Gladman DD, Urowitz MB, Goldsmith $\mathrm{CH}$, et al. The reliability of the Systemic Lupus International Collaborating Clinics/American College of Rheumatology Damage Index in patients with systemic lupus erythematosus. Arthritis Rheum 1997;40:809-13.

34. Nived $\mathrm{O}$, Jonsen A, Bengtsson AA, et al. High predictive value of the Systemic Lupus International Collaborating Clinics/American
College of Rheumatology damage index for survival in systemic lupus erythematosus. J Rheumatol 2002;29:1398-400.

35. Radloff LS. The CES-D scale: a self-report depression scale for research in the general population. Appl Psychol Meas 1977;1:385-401.

36. Huang B, Sivaganesan S, Succop P, et al. Statistical assessment of mediational effects for logistic mediational models. Stat Med 2004;23:2713-28

37. Cuffee YL, Hargraves JL, Rosal M, et al. Reported racial discrimination, trust in physicians, and medication adherence among inner-city African Americans with hypertension. Am J Public Health 2013;103:e55-62.

38. Hausmann LR, Kwoh CK, Hannon MJ, et al. Perceived racial discrimination in health care and race differences in physician trust. Race Soc Probl 2013:5:113-20.

39. Petri M, Perez-Gutthann S, Longenecker JC, et al. Morbidity of systemic lupus erythematosus: role of race and socioeconomic status. Am J Med 1991;91:345-53.

40. Broman CL, Mavaddat R, Hsu S. The experience and consequences of perceived racial discrimination: a study of AfricanAmericans. J Black Psychology 2000;26:165-80.

41. Paradies Y. A systematic review of empirical research on self-reported racism and health. Int J Epidemiol 2006;35:888-901

42. Crawley LM, Ahn DK, Winkleby MA. Perceived medical discrimination and cancer screening behaviors of racial and ethnic minority adults. Cancer Epidemiol Biomarkers Prev 2008;17:1937-44.

43. Helmes AW, Bowen DJ, Bengel J. Patient preferences of decision-making in the context of genetic testing for breast cancer risk. Genet Med 2002;4:150-7.

44. Johnson RL, Saha S, Arbelaez JJ, et al. Racial and ethnic differences in patient perceptions of bias and cultural competence in health care. J Gen Intern Med 2004;19:101-10.

45. Karlson EW, Daltroy LH, Lew RA, et al. The relationship of socioeconomic status, race, and modifiable risk factors to outcomes in patients with systemic lupus erythematosus. Arthritis Rheum 1997;40:47-56.

46. Chang E, Abrahamowicz M, Ferland D, et al. Comparison of the responsiveness of lupus disease activity measures to changes in systemic lupus erythematosus activity relevant to patients and physicians. J Clin Epidemiol 2002;55:488-97.

47. Julian LJ, Tonner C, Yelin E, et al. Cardiovascular and disease-related predictors of depression in systemic lupus erythematosus. Arthritis Care Res (Hoboken) 2011;63:542-9.

48. Knight $\mathrm{A}$, Weiss $\mathrm{P}$, Morales $\mathrm{K}$, et al. Depression and anxiety and their association with healthcare utilization in pediatric lupus and mixed connective tissue disease patients: a cross-sectional study. Pediatr Rheumatol Online J 2014;12:42.

49. Riolo SA, Nguyen TA, Greden JF, et al. Prevalence of depression by race/ethnicity: findings from the National Health and Nutrition Examination Survey III. Am J Public Health 2005;95:998-1000.

50. Myaskovsky L, Burkitt KH, Lichy AM, et al. The association of race, cultural factors, and health-related quality of life in persons with spinal cord injury. Arch Phys Med Rehabil 2011;92:441-8. 